\title{
Kinetics Of Charge Generation During Formation of Hf And Zr Silicate Dielectrics
}

Theodosia Gougousi, M. Jason Kelly, and Gregory N. Parsons

Dept. of Chemical Engineering, NC State University, Raleigh, NC 27695, U.S.A.

\begin{abstract}
Understanding charged defects in high dielectric constant insulators is a critical challenge for advanced devices. We have formed thin $\mathrm{Zr}$ and $\mathrm{Hf}$ silicates by oxidation of thin metal films sputtered on clean $\mathrm{Si}(100)$ and studied the effect of oxidation time (15 to 300s) and temperature $\left(600\right.$ or $\left.900^{\circ} \mathrm{C}\right)$ on the flatband voltage using capacitance vs. voltage measurements. We find that the thermal budget during oxidation and the type of oxidizing agent (slow vs. fast) affect the amount of fixed charge in the film significantly. Oxidation of $0.8 \mathrm{~nm}$ of $\mathrm{Zr}$ metal on $\mathrm{Si}$ at $600 \mathrm{C}$ in $\mathrm{N}_{2} \mathrm{O}$ for $15 \mathrm{~s}$ results in EOT $=1.2 \mathrm{~nm}$ and a shift in the flatband voltage by $\sim-0.2 \mathrm{~V}$ indicating generation of positive fixed charge. Oxidation of similar films for $300 \mathrm{~s}$ result in EOT $=2.8 \mathrm{~nm}$ and shift of the flatband voltage by $\sim-0.95 \mathrm{~V}$. Hf films oxidized in $\mathrm{N}_{2} \mathrm{O}$ also show increased concentrations of fixed charge for longer oxidation times. By comparison, Si oxidized in the same environment does not show this extent of flatband voltage shift. A significantly reduced charge generation rate is observed for $\mathrm{Hf}$ oxidation under low $\mathrm{O}_{2}$ partial pressure. Extended oxidations (up to $1 \mathrm{~h}$ ) result in increased EOT and a slight decrease in the charged defect state density. Forming Gas Anneal (FGA) results in partial neutralization of the charge. FGA after the Al gate deposition also leads to significant decrease of the EOT (from 2.7 to $2.1 \mathrm{~nm}$ ) indicating significant reaction of the film with the gate metal. X-ray photoelectron spectroscopy for thin films indicates formation of $\mathrm{Zr}$ and Hf-silicates. However, for thick Hf films the low $\mathrm{O}_{2}$ oxidation process results in less silicon incorporation in the film as compared to films oxidized in $\mathrm{N}_{2} \mathrm{O}$. Results suggest that understanding oxidation mechanisms will be important in isolating and controlling fixed charge in high-k dielectrics.
\end{abstract}

\section{INTRODUCTION}

Approaching the tunneling limit for the $\mathrm{SiO}_{2}$ gate dielectric in CMOS devices has fueled research for an alternative material with a higher dielectric constant that will permit the use of physically thicker films. Several prospective materials are currently under investigation, mainly oxides and silicates of group III and IV metals. Formation of low-k interfacial layers and significant concentration of fixed charge are two of the main shortcomings of most materials investigated to date. ${ }^{1}$ For some materials, fixed charge appears to be an intrinsic property and as such, very hard to neutralize. ${ }^{2}$ In other cases, charge is generated as a result of processing conditions. Formation of interfacial layers and mixing of $\mathrm{Si}$ in the film are also shown to occur as a result of the deposition process. ${ }^{3}$ In this article, we present our findings regarding the effect of the oxidation rate and thermal budget on the Si content and the amount of charged defects detected in ultra-thin $\mathrm{Hf}$ and Zr-based high-k films on Si. 


\section{EXPERIMENTAL}

We deposit $0.8-1.0 \mathrm{~nm}$ of $\mathrm{Hf}$ or $\mathrm{Zr}$ metal on cleaned $\mathrm{Si}(100)$ substrates using dc sputtering as described by Chambers. ${ }^{4}$ After metal deposition, the films are oxidized ex-situ in a tube furnace at $600^{\circ} \mathrm{C}$ in the presence of $\mathrm{N}_{2} \mathrm{O}$, a process that is known to cause rapid oxidation. Another set of metal films is oxidized using the impurity $\mathrm{O}_{2}$ present in dry $\mathrm{N}_{2}$ at atmospheric pressure, following the procedure initially described by $\mathrm{B}$. H. Lee et al. ${ }^{5}$ As a control experiment, several clean silicon substrates are oxidized in $\mathrm{N}_{2} \mathrm{O}$ for 20 to 60 min which produces $\sim 1.8$ to $2.5 \mathrm{~nm}$ of $\mathrm{SiO}_{2}$.

Metal-Insulator-Semiconductor capacitors are fabricated by resistive heating evaporation of $\mathrm{Al}$ through shadow masks. Capacitance vs. voltage (CV) measurements are performed with a HP4284 impedance meter at 1MHz. Capacitor surface areas (typically $4 \times 10^{-4} \mathrm{~cm}^{2}$ ) is determined by optical microscopy. The NCSU program ${ }^{6}$ that corrects for quantum mechanical effects is used to obtain the Equivalent Oxide Thickness (EOT) and the position of the flatband voltage. For each sample the CV characteristics for several capacitors are measured and the results are averaged. Compositional analysis of the samples is performed by X-ray Photoelectron Spectroscopy (XPS) using a Riber LAS3000 (MAC2 analyzer, Mg Ko (hv=1253.6 eV) nonmonochromatic X-ray source) at $75^{\circ}$ take-off-angle with $0.1 \mathrm{eV}$ step size. We compensate for sample charge effects by setting the adventitious $\mathrm{C} 1 \mathrm{~s}$ peak to a binding energy of $285.0 \mathrm{eV}$.

\section{RESULTS AND DISCUSSION}

Figure 1a shows the $\mathrm{CV}$ curves for $0.8 \mathrm{~nm} \mathrm{Zr}$ films oxidized in $\mathrm{N}_{2} \mathrm{O}$ at $600^{\circ} \mathrm{C}$ for 15 to $300 \mathrm{~s}$. Figures $1 \mathrm{~b}$ and $1 \mathrm{c}$ present the flatband voltage $\left(\mathrm{V}_{\mathrm{FB}}\right)$ and the equivalent oxide thickness (EOT) as a function of the oxidation time respectively. The data points represent the average of measurements on several capacitors of the same sample and the error bars represent one standard deviation. If no error bar is shown, the size of the error bar is equal to (or less than) the size of the data point symbol. The expected position of $\mathrm{V}_{\mathrm{FB}}$, calculated from the vacuum work function of the Al gate and the doping of the Si substrate is $\sim 0 \mathrm{~V}$. We find that an increase in the oxidation time leads to smaller capacitances and more negative shift in the CV curve. The EOT more than doubles, from $\sim 1.2 \mathrm{~nm}$ for $15 \mathrm{~s}$ oxidation to $2.8 \mathrm{~nm}$ for $300 \mathrm{~s}$ oxidation, due to the formation of a
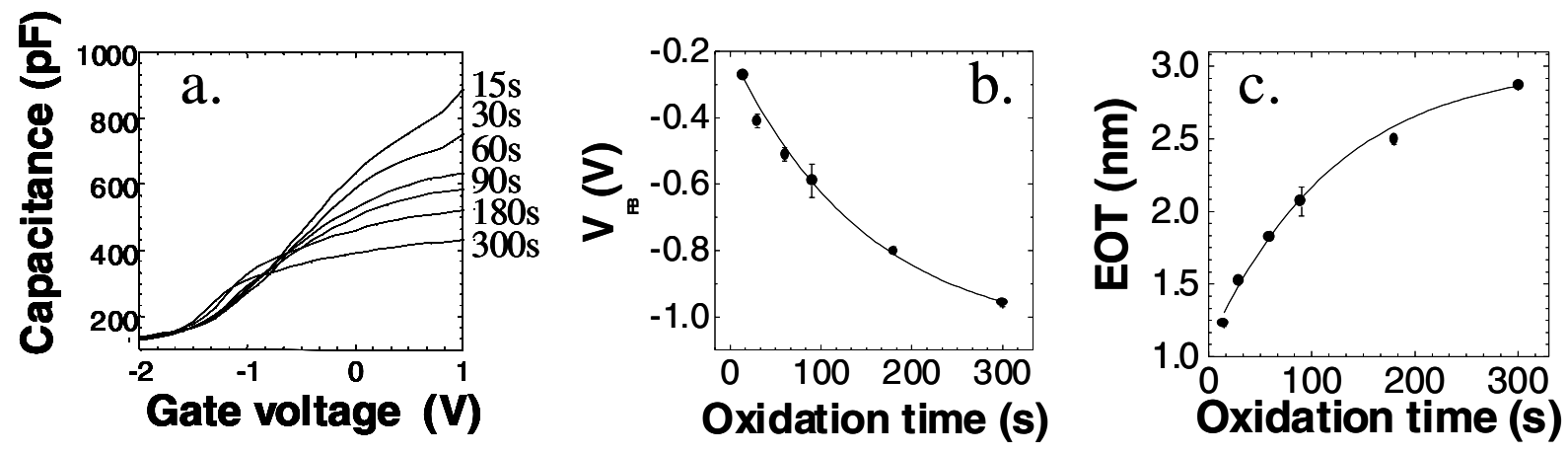

Figure 1. Capacitance vs. Voltage curves (Fig. 1a) for $0.8 \mathrm{~nm} \mathrm{Zr}$-metal films oxidized in $\mathrm{N}_{2} \mathrm{O}$ with $\mathrm{Al}$ gates as a function of oxidation time (legend). The flatband voltage $\left(\mathrm{V}_{\mathrm{FB}}\right)$ (Fig. 1b) and EOT (Fig. 1c) vs. oxidation time plots show that extended oxidation results in oxidation of the interface that is accompanied by generation of positive fixed charge in the film. 


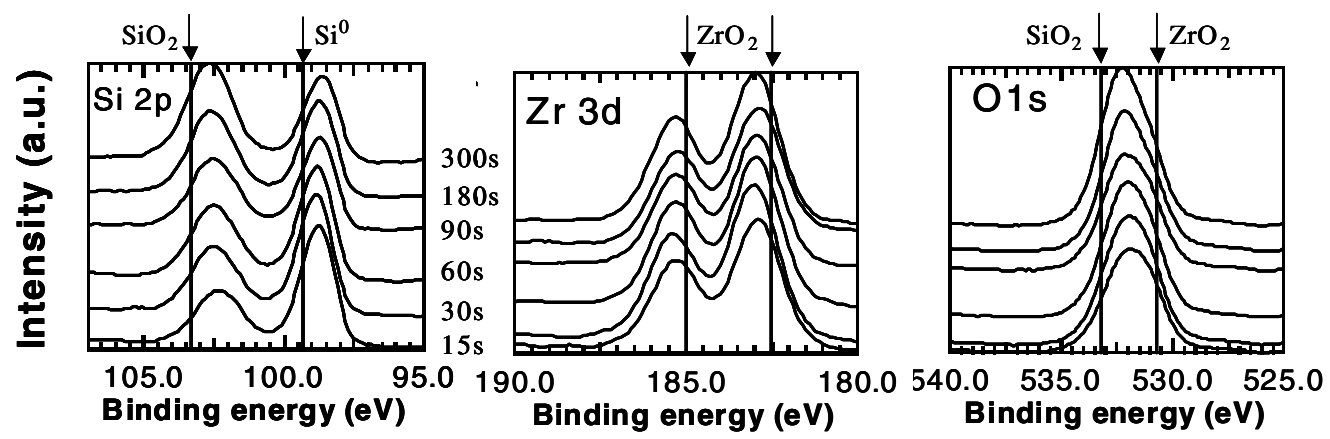

Figure 2. Si2p, $\mathrm{Zr3d}$ and O1s XP spectra for $0.8 \mathrm{~nm} \mathrm{Zr}$ metal films on Si oxidized at $600^{\circ} \mathrm{C}$ in $\mathrm{N}_{2} \mathrm{O}$. The oxidation time is given in the legend. The film is $\mathrm{ZrSiO}$ with a substantial $\mathrm{SiO}_{2}$ interfacial layer.

thick interfacial layer. The flatband voltage shifts from $\sim-0.25 \mathrm{~V}$ for the 15 s process to $\sim-0.95 \mathrm{~V}$ for the 300s process, indicating the generation of substantial amounts of positive fixed charge in the film.

$\mathrm{Si} 2 \mathrm{p}, \mathrm{Zr} 3 \mathrm{~d}$ and O1s XP spectra for the Zr samples are shown in Fig. 2. The location and width of the $\mathrm{Si} 2 \mathrm{p}$ peak at $\sim 102.5 \mathrm{eV}, \mathrm{O} 1 \mathrm{~s}$ peak at $\sim 532 \mathrm{eV}$ indicates that the films are silicates ${ }^{7,8}$ with $\mathrm{SiO}_{2}$ at the interface. The ratio of the $\mathrm{ZrSiO} / \mathrm{SiO}_{2}$ to the substrate $\mathrm{Si}^{0}$ peak areas increases with oxidation indicating further oxidation of the interface. The $\mathrm{Si}^{0}$ peak is detected for all samples and appears at a lower binding energy than expected. Opila et al. have reported and explained the relationship between fixed charge and the position of the $\mathrm{Si}^{0}$ peak in XP spectra for Hf and $\mathrm{Zr}$ silicate films. ${ }^{9}$ The shift in $\mathrm{Si}^{0}$ peak in our films can be explained by the existence of fixed charge in the layers that the substrate photoelectrons have to transverse.

Figure 3 a shows the $\mathrm{CV}$ curves for $0.8 \mathrm{~nm} \mathrm{Hf}$-metal films oxidized in $\mathrm{N}_{2} \mathrm{O}$ at $600^{\circ} \mathrm{C}$ for 30 to 300s. In general, we find that an increase in the oxidation times leads to smaller capacitances (i.e. thicker films) but the shape and position of the curve remains practically unchanged for oxidation up to 120s. For the sample oxidized for 300s we observe a reduction in the capacitance and a significant shift of the curve to more negative voltage. Figure $1 \mathrm{~b}$ is a plot of the C-V curves for $0.8 \mathrm{~nm} \mathrm{Hf}$ films oxidized in the $\mathrm{N}_{2}$ ambient for 45,90 and $300 \mathrm{~s}$. The capacitance of the gate stack decreases with longer oxidation, but the rate of decline is significantly slower than for $\mathrm{N}_{2} \mathrm{O}$ oxidation, and the position of the curve is not significantly affected.

Fig. 4a presents the equivalent oxide thickness (EOT) as a function of the oxidation time
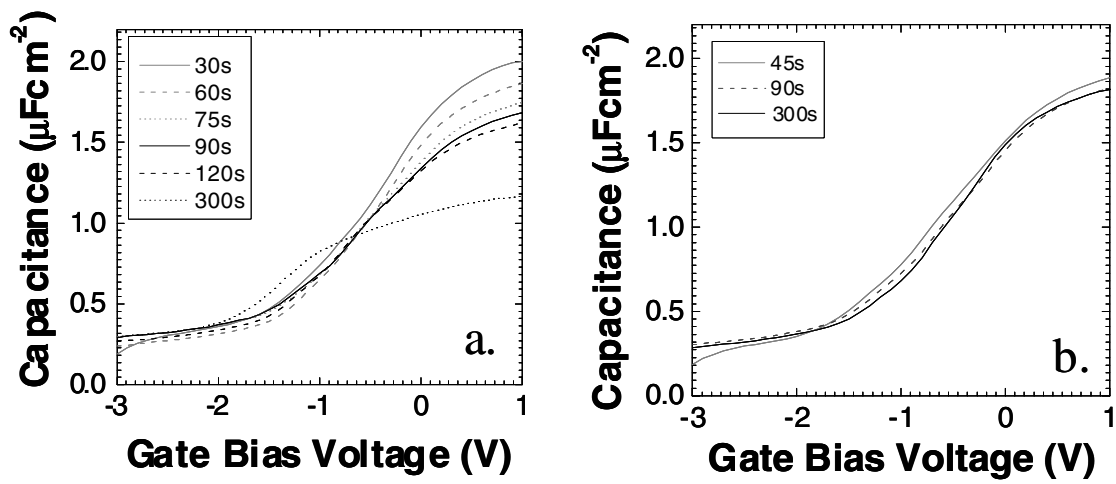

Figure 3. Capacitance vs. Voltage measurements for $8 \AA$ Hf-metal films oxidized in $\mathrm{N}_{2} \mathrm{O}$ (Fig. 3a) and N2 (Fig. 3b) with Al gates as a function of oxidation time (legend). 

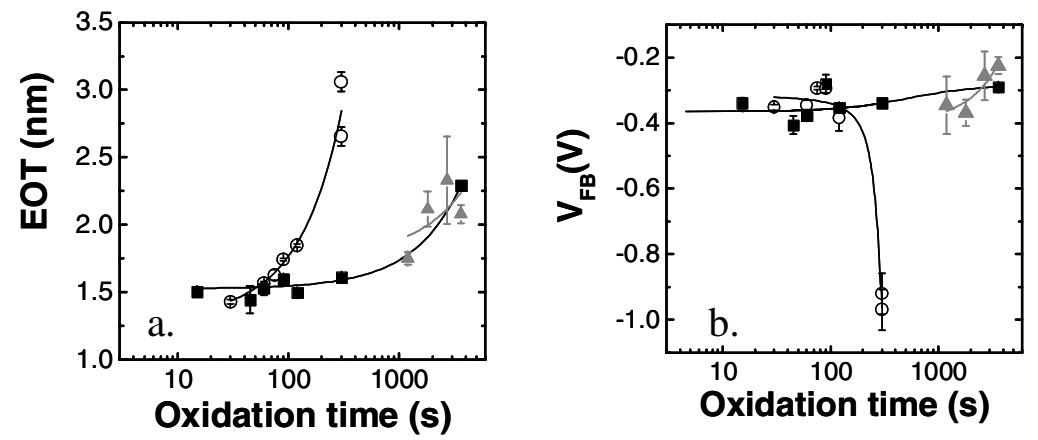

Figure 4. Equivalent Oxide Thickness (EOT) and flatband voltage $\mathrm{V}_{\mathrm{FB}}$ vs. oxidation time for $0.8 \mathrm{~nm}$ Hf-metal films oxidized in $\mathrm{N}_{2}$ (squares) and $\mathrm{N}_{2} \mathrm{O}$ (circles), and for $\mathrm{H}$-terminated $\mathrm{Si}$ oxidized in $\mathrm{N}_{2} \mathrm{O}$ (triangles).

for Hf films oxidized by $\mathrm{N}_{2}$ and $\mathrm{N}_{2} \mathrm{O}$, and the control $\mathrm{SiO}_{2}$ films. For oxidization in $\mathrm{N}_{2} \mathrm{O}$ (circles), the EOT increases by almost a factor of two, from $\sim 1.4 \mathrm{~nm}$ for $30 \mathrm{~s}$ oxidation to $2.6 \mathrm{~nm}$ for 300s oxidation. The $\mathrm{N}_{2}$ process (squares in Fig. 4a) results in negligible increase in the EOT from $1.5 \mathrm{~nm}$ to $\sim 1.6 \mathrm{~nm}$ for oxidation between 15 and $300 \mathrm{~s}$, and increases to $\sim 2.3 \mathrm{~nm}$ after $1 \mathrm{~h}$ oxidation. The EOT for the control $\mathrm{SiO}_{2}$ film data (triangles) oxidized in $\mathrm{N}_{2} \mathrm{O}$ varies between 1.6 and $2.2 \mathrm{~nm}$, comparable in thickness to the interfacial layer produced during $\mathrm{N}_{2} \mathrm{O}$ oxidation of Hf-metal films. The $\mathrm{SiO}_{2}$ data exhibit significant scattering, which is probably due to the poor quality of $\mathrm{SiO}_{2}$ produced with this technique. Figure $4 \mathrm{~b}$ shows the flatband voltage $\left(\mathrm{V}_{\mathrm{FB}}\right) \mathrm{vs}$. oxidation time for $\mathrm{N}_{2} \mathrm{O}$ (open circles), $\mathrm{N}_{2}$ ambient (solid squares), and control $\mathrm{SiO}_{2}$ films (triangles). For the $\mathrm{N}_{2}$ process, prolonged exposure leads to marginal reduction in the $\mathrm{V}_{\mathrm{FB}}$ from $\sim-0.375$ to $-0.3 \mathrm{~V}$. For the $\mathrm{N}_{2} \mathrm{O}$ process, the $\mathrm{V}_{\mathrm{FB}}$ is comparable to that for the $\mathrm{N}_{2}$ process and remains almost constant at $-0.35 \mathrm{~V}$ for oxidations up to $120 \mathrm{~s}$. For $300 \mathrm{~s}$, though, $\mathrm{V}_{\mathrm{FB}}$ becomes substantially more negative. For the control $\mathrm{SiO}_{2}$ films, $\mathrm{V}_{\mathrm{FB}}$ decreases somewhat for longer

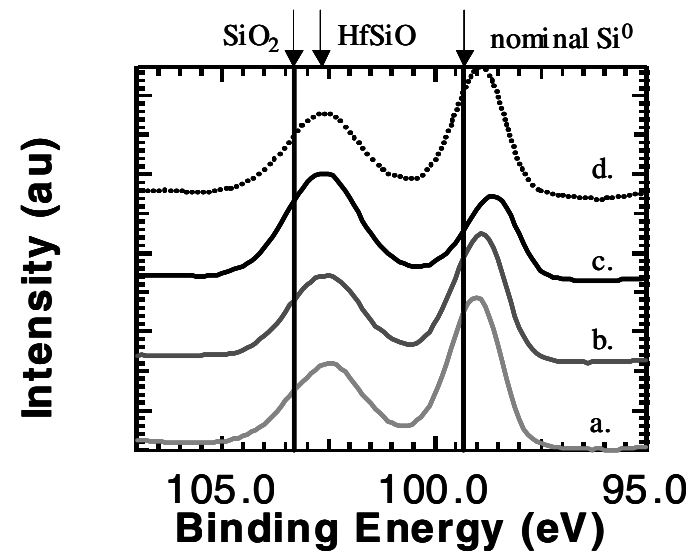

Figure 5. XP spectra for $0.8 \mathrm{~nm}$ Hf-metal films oxidized in $\mathrm{N}_{2} \mathrm{O}$ for (a) $30 \mathrm{~s}$ (b) $90 \mathrm{~s}$ (c) 300 s and (d) $\mathrm{N}_{2}$ for 300 s. Spectra (a), (b) and (d) are practically identical and correspond to samples with comparable electrical properties. The $\mathrm{HfSiO} / \mathrm{SiO}_{2}$ peak is enhanced in spectrum (c), result of the fast interface oxidation achieved in $\mathrm{N}_{2} \mathrm{O}$. oxidation times, tracking fairly well the trend exhibited by the $\mathrm{N}_{2}$ process.

Si2p XP spectra for some of the samples from Figure 4 are shown in Fig. 5. The substrate peak $\mathrm{Si}^{0}$ can be detected for these samples and the peak at $\sim 102.5 \mathrm{eV}$ indicates that the films are silicates ${ }^{7,8}$ with some $\mathrm{SiO}_{2}$ at the interface. For the samples (a) and (b) oxidized in $\mathrm{N}_{2} \mathrm{O}$ for 30 and $90 \mathrm{~s}$ respectively, the ratio of the $\mathrm{HfSiO} / \mathrm{SiO}_{2}$ to the $\mathrm{Si}^{0}$ peak areas is approximately the same and less than 1 . However, for sample (c) oxidized in $\mathrm{N}_{2} \mathrm{O}$ for 300 s we observe substantial oxidation of the interface as evidenced by the increase in the $\mathrm{HfSiO}_{x} / \mathrm{SiO}_{2}$ peak area. The spectrum for the sample (d) oxidized for 300 s in $\mathrm{N}_{2}$ is comparable to spectrum (a) oxidized for 30 seconds in $\mathrm{N}_{2} \mathrm{O}$. The $\mathrm{Si}^{0}$ peaks appear at a lower binding energy than expected 
corroborating similar observations for the Zr-based films. Based on the electrical and the XPS data for both the $\mathrm{Hf}$ and $\mathrm{Zr}$ films we can conclude that the increase in the EOT results from an increase in the thickness of the $\mathrm{SiO}_{2}$ interfacial layer. In general, it is believed that $\mathrm{SiO}_{2}$ leads to a better quality silicon interface than metal oxide. For $\mathrm{N}_{2} \mathrm{O}$ oxidation we find that rapid oxidation of the interface is accompanied by trapping of charge in both the $\mathrm{Hf}$ and $\mathrm{Zr}$ films. The data indicate that the growth rate of the interfacial layer correlates with the amount of charge generated in the film. For the Zr-based films, it appears that the amount of charge trapped in the film is proportional to the thickness of interface layer, which is proportional to the oxidation time. The Hf-based films appear more resistant to the generation of charged defects. For oxidation times in $\mathrm{N}_{2} \mathrm{O}$ up to 120 s there is no substantial effect. However, oxidation in $\mathrm{N}_{2} \mathrm{O}$ at $600^{\circ} \mathrm{C}$ in for $300 \mathrm{~s}$ results to the growth of $\sim 1.5 \pm 0.2 \mathrm{~nm}$ of interfacial $\mathrm{SiO}_{2}$ and a substantial shift of the flatband voltage. For the control samples, much slower growth of 1.6-2.2nm of $\mathrm{SiO}_{2}$ on $\mathrm{Si}$ in $\mathrm{N}_{2} \mathrm{O}$ in 20-60 min leads to significantly lower trapped charge. For the Hf samples oxidized in O-deficient environment growth of $0.7 \mathrm{~nm}$ of interfacial $\mathrm{SiO}_{2}$ at $600^{\circ} \mathrm{C}$ in $1 \mathrm{~h}$ also results in marginal reduction in the amount of charge in the film. It appears that the defect generation mechanism involves participation of the metal atoms. High growth rate of the interfacial layer facilitates trapping of hetero-atoms near the interface. Where the covalent $\mathrm{SiO}_{2}$ network is disrupted by the introduction of ionic bonding due to the metal atom, defects are generated. This mechanism may cause the difference in the film quality observed for fast vs. slow oxidation. It is not clear, though, why there is difference in the quality of the $\mathrm{Hf}$ and $\mathrm{Zr}$ films oxidized in $\mathrm{N}_{2} \mathrm{O}$.

Generation of positive fixed charge has been observed during postdeposition reoxidation of $\mathrm{ZrO}_{2} / \mathrm{SiO}_{2}$ gate stacks formed by atomic layer deposition, and the fixed charge has been attributed to formation of overcoordinated $\mathrm{O}$ center induced by a large density of $\mathrm{H}$ atoms originating from the $\mathrm{H}_{2} \mathrm{O}$ precursor. ${ }^{10}$ Our process if $\mathrm{H}_{2} \mathrm{O}$ free, and IR measurements on thick samples do not show any appreciable absorption of $\mathrm{H}_{2} \mathrm{O}$ even after long ambient exposures. ${ }^{11}$ Clearly more detailed experiments are required to trace the origin of this type of charge.

FGA $\left(10 \% \mathrm{H}_{2}\right.$ in $\mathrm{N}_{2}$ for $30 \mathrm{~min}$ at $\left.400^{\circ} \mathrm{C}\right)$ performed on the Hf-based samples results in partial neutralization of the charges when performed before metallization, and almost complete removal after $\mathrm{Al}$ deposition. In the latter case, however, neutralization of the charge is accompanied by significant increase in the gate capacitance indicative of reaction at the dielectric-gate metal interface. FGA performed on $\mathrm{Zr}$ samples after the deposition of the $\mathrm{Al}$ gate also indicates significant reaction of the film with the gate metal. While, FGA may remove part of these defects, from a reliability standpoint it is desirable to avoid introducing the charges in the first place, as further thermal treatment and stress on the device may lead to desorption of the
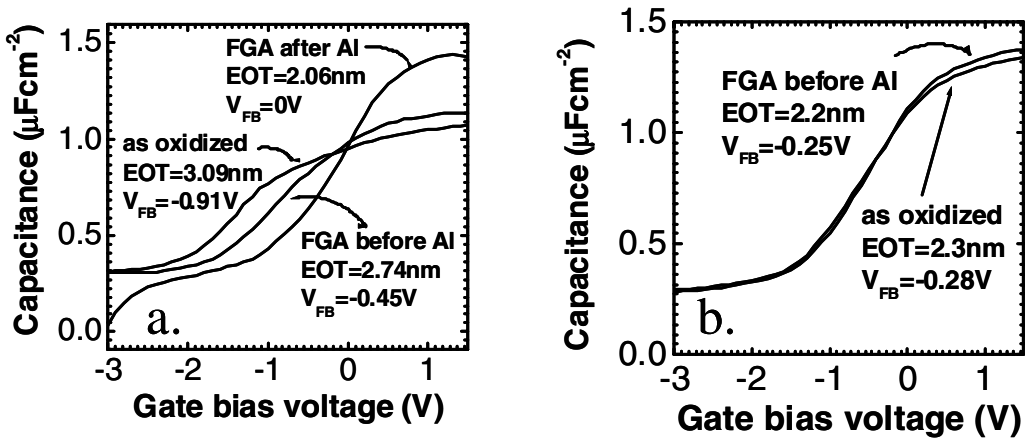

Figure 6. The effect of FGA on the CV curves of $\mathrm{Hf}$ films oxidized in $\mathrm{N}_{2} \mathrm{O}$ (a) and $\mathrm{N}_{2}$ (b). 


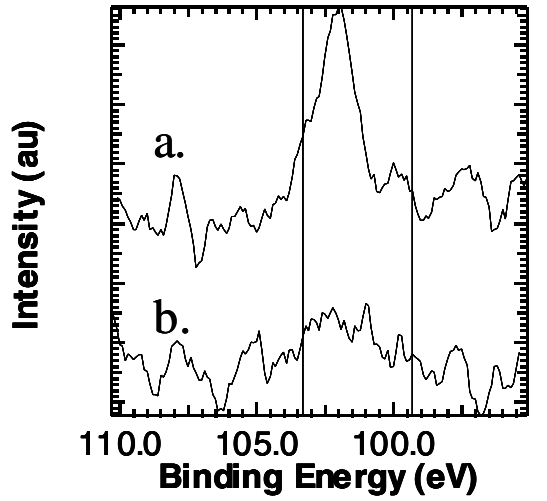

Figure 7. Si $2 p$ XP spectra for $45 \mathrm{~nm}$ Hf- metal films oxidized in (a) $\mathrm{N}_{2} \mathrm{O}$ and (b) $\mathrm{N}_{2}$. The film oxidized in $\mathrm{N}_{2} \mathrm{O}$ shows $\mathrm{Si}$ incorporation in the film.
$\mathrm{H}$-atoms and regeneration of the defects, which will deteriorate carrier mobility in devices significantly.

The effect of the oxidizing agent on the film composition was also examined. Figure 7 displays the Si2p XP spectra for two similar thick $(\sim 45 \mathrm{~nm}$ metal) Hf-based films, one oxidized in $\mathrm{N}_{2} \mathrm{O}$ for 10min (sample (a)) and the other oxidized in $\mathrm{N}_{2}$ (sample(b)) for $10 \mathrm{~min}$. We observe that for the film oxidized in $\mathrm{N}_{2} \mathrm{O}$ there is a peak at $\sim 102 \mathrm{eV}$ indicative of silicate bonding in the film. For the film oxidized at low $\mathrm{O}_{2}$ partial pressure this spectral region is practically flat. The $\mathrm{O} 1 \mathrm{~s}$ and $\mathrm{Hf} 4 \mathrm{~d}$ spectra are consistent with formation of a top silicate layer for sample (a) and a $\mathrm{HfO}_{2}$ layer for sample (b). It appears that fast oxidation of a Hf-metal film results not only in significant oxidation of the dielectric/Si

interface but also promotes Si incorporation in the bulk of the film. These finding are consistent with observations reported by Rangarajan et al. ${ }^{12}$ for CVD Hf-based high-k films.

\section{ACKNOWLEDGMENTS}

Financial support from SRC and NSF 00-72784 is gratefully acknowledged.

\section{REFERENCES:}

1

G.D. Wilk, R.M. Wallace and J.M. Anthony, J. Appl. Phys. 89(10), 5243 (2001) and references therein.

M. Copel, E. Cartier, and F. M. Ross, Appl. Phys. Lett. 78(11), 1607 (2001)

D. Niu, R.W. Ashcraft, M.J. Kelly, J.J. Chambers, T.M. Klein, and G.N. Parsons, J. Appl. Phys. 91(9) (2002),

J.J. Chambers and G.N. Parsons, J. Appl. Phys. 90 (2), 918 (2001)

B. H. Lee, L. Kang, R. Nieh W. J. Qi, and J. C. Lee, Appl. Phys. Lett. 76 (14), 1926 (2000)

N. Yang, K. W. Henson, J. R. Hauser, and J. J. Wortman, IEEE Trans. Electron Devices 46, 1464 (1999)

Y. Hoshino, Y. Kido, K. Yamamoto, S. Hayashi, and M. Niwa, Appl. Phys. Lett. 81 (14) 2659 (2002)

P. D. Kirsch, C. S. Kang, J. Lozano, J. C. Lee, and J. G. Ekerdt, J. Appl. Phys. 91 (7), 4353 (2002)

R. L. Opila, G. D. Wilk, M. A. Alam, R. B. van Dover, and B. W. Busch, Appl. Phys. Lett. 81 (10), 1788 (2002)

M. Houssa, V. V. Afanas'ev, A. Stesmans, and M. M. Heyns, Appl. Phys. Lett. 77 (12), 1885 (2000)

T. Gougousi, and G. N. Parsons, in preparation.

V. Rangarajan, H. Bhandari, and T. M. Klein, Thin Sol. Films, 419, 1 (2002) 